\title{
The influential factors for achieving universal health coverage in Iran: a multimethod study
}

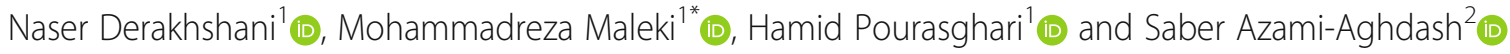

\begin{abstract}
Background: The initial purpose of healthcare systems around the world is to promote and maintain the health of the population. Universal Health Coverage (UHC) is a new approach by which a healthcare system can reach its goals. World Health Organization (WHO) emphasized maximum population coverage, health service coverage, and financial protection, as three dimensions of UHC. In progress for achieving UHC, recognizing the influential factors allows us to accelerate such progress. Therefore, this study aimed to identify the influential factors to achieve UHC in Iran.

Methods: This is a multi-method study was conducted in four phases: First, a systematic review of the literature was conducted to identify the factors in PubMed, Web of Science, Embase, Scopus, ProQuest, Cochrane library, and Science Direct databases, and hand searching google scholar search engine. For recognizing the unmentioned factors, a qualitative study consisting of one session of Focus Group Discussion (FGD) and five semi-structured interviews with experts was designed. The extracted factors were merged and categorized by round table discussion. Finally, the pre-categorized factors were refined and re-categorized under the health system's control knobs framework during three expert panel sessions.
\end{abstract}

Results: Finally, 33 studies were included. Eight hundred two factors were extracted through systematic review and 96 factors through FGD and interviews (totally, 898). After refining them by the experts' panel, 105 factors were categorized within the control knob framework (financing 19, payment system7, Organization 23, regulation and supervision 33, Behavior 11, and Others 12). The majority of the identified factors were related to the "regulation and supervision" dimension, whilst the "payment system" entailed the fewest. The political commitment during political turmoil, excessive attention to the treatment, referral system, paying out of pocket(OOP) and protection against high costs, economic growth, sanctions, conflict of interests, weakness of the information system, prioritization of services, health system fragmented, lack of managerial support and lack of standard benefits packages were identified as the leading factors on the way to UHC.

\footnotetext{
*Correspondence: mrmaleki43@gmail.com

1 Department of Health Services Management, School of Health Management and Information Sciences, Iran University of Medical Sciences, Tehran, Iran Full list of author information is available at the end of the article
}

(c) The Author(s). 2021 Open Access This article is licensed under a Creative Commons Attribution 4.0 International License, which permits use, sharing, adaptation, distribution and reproduction in any medium or format, as long as you give appropriate credit to the original author(s) and the source, provide a link to the Creative Commons licence, and indicate if changes were made. The images or other third party material in this article are included in the article's Creative Commons licence, unless indicated otherwise in a credit line to the material. If material is not included in the article's Creative Commons licence and your intended use is not permitted by statutory regulation or exceeds the permitted use, you will need to obtain permission directly from the copyright holder. To view a copy of this licence, visit http://creativecommons.org/licenses/by/4.0/ The Creative Commons Public Domain Dedication waiver (http://creativecommons.org/publicdomain/zero/1.0/) applies to the data made available in this article, unless otherwise stated in a credit line to the data. 
Conclusion: Considering the distinctive role of the context in policymaking, the identification of the factors affecting UHC accompanying by the countries' experiences about UHC, can boost our speed toward it. Moreover, adopting a long-term plan toward UHC based on these factors and the robust implementation of it pave the way for Iran to achieve better outcomes comparing to their efforts.

Keywords: Influential factors, Universal health coverage, Health system, Control knobs, Systematic review, Iran

\section{Background}

Universal Health Coverage (UHC) has been introduced as a viable solution to promote, restore, and/or maintain the health of the population in countries $[1,2]$. UHC has been defined as a way to provide quality health services to the destined population based on their health needs without suffering financial hardship [1,3-5]. Furthermore, UHC is a way of promoting the population's quality of life while ensuring financial risk protection, equity, and access to essential and quality health services [6-11].

In the past two decades, along with some HighIncome Countries (HICs) that have achieved UHC, there was a substantial increase in the number of Low and Middle-Income countries (LMICs) showing great endeavors to reach the state of the sample countries [12, 13]. As, in the coming decades, most Asian and African countries will be able to implement basic and effective plans to achieve UHC by acquiring sufficient abilities to provide their essential resources in the health system for their country $[14,15]$.

Iran is one of the countries that seek to reach UHC in the next coming decade. In Iran, both the public and private sectors provide health services. However, the public sector has the upper hand in this issue [16]. The public health sector in Iran provides primary, secondary, and tertiary health services. On the other hand, the private sector focuses mainly on secondary and tertiary health care in urban areas [17]. To improve the health system and move towards UHC, Iran designed and implemented the Health Reform Program (HRP) in 2014. According to this reform policy, eight programs have been introduced in three steps aiming at UHC. The first step was to decrease OOP payments, extending insurance coverage, and improving the quality of health services in target populations Second step was about providing all services, drugs, and equipment needed by the inpatient wards, and the third one was about updating the tariffs on medical services [18-20]. Generally, the final destination of HRP was to improve the health indicators, to ensure equity in the delivery of health services, and to reduce health costs. The results of HRP in the short term indicated a decline in catastrophic health costs [18]. The health status of Iranian has been improved during the last decade's thanks to the health networks where primary healthcare was provided for both rural and urban populations; however, many weaknesses and challenges are threatening the health system, such as high degrees of OOP payments [21], limited financial resources, increase in unofficial payments to the physicians [22], lack of community participation in solving health problems [23, 24], financial constraints, lack of clarity in tariffs setting mechanisms [25], and difficulties affecting the system due to international sanctions against Iran [26, 27].

Having the capabilities and potential to do so, Iran can take benefit of the experiences of LMICs such as Turkey [28] and Thailand [29] that have achieved UHC previously. This country has greatly reduced its distance to UHC compared to 22 LMICs as it seeks to mobilize resources, carry out reforms in policies, and fulfill political commitments to this mean $[2,30,31]$. Although all countries pursue the same goal, the method and timings are different based on the structure and available resources of the countries as well as the unique factors affecting countries [9]. For instance, countries such as Germany and Japan had achieved UHC in 127 and 36 years according to their specific structure and challenges [32].

Universal health coverage, as a comprehensive and new policy that overwhelm all parts of the health system and even other sectors, is influenced by many factors, such as political sustainability [33, 34], economic growth [35, 36], fragmentation in the health system [37-39], etc. Therefore, it is vital to set up the influential factors within a framework/model, to ensure the applicability of the policy at different levels of the health system. Also, it is essential to identify these factors according to the country's unique circumstances. Because the factors act as a role model for health system managers to have due policy-makings. Moreover, the introduction of such factors results in the accurate, transparent, and accountable form of resource allocation which is a bottleneck in health systems. Furthermore, it seems that presenting the factors identified in the form of a framework increases the applicability and usability of the framework by policymakers and senior managers not only in the health system of Iran but also in other countries. Therefore, this study aimed to identify the factors that can facilitate or hinder the speed of achieving UHC in Iran.

\section{Methods}

This study was conducted in four phases: (1) systematic review of relevant studies; (2) Qualitative Study: (Focus Group Discussion (FGD) \& semi-structured interview); 
(3) merging factors based on Framework-Analysis; (4) refining and finalizing the factors in control knob framework through expert panels.

\section{Phase 1: systematic review}

A systematic review was conducted in accordance with Preferred Reporting Items for Systematic Reviews and Meta-analysis (PRISMA) [40].

\section{Search strategy and information sources}

The required data were gathered by searching on $1 \mathrm{Au}$ gust 2020 and the search was updated on April 18, 2021, in the following databases: PubMed, EMBASE, Scopus, ProQuest, ISI Web of Science, Cochrane Library, Science Direct, and hand searching through Google Scholar search engine. Also, for finding national studies on UHC, the SID and MagIran were searched in Persian. Each database was searched according to its strategy. World Health Organization (WHO) and World Bank (WB) databases that host reports related to UHC were also searched. The key search terms selection was done by experts and using the mesh, which included 'universal health coverage, 'universal coverage', 'universal healthcare coverage', 'universal health care coverage', 'UHC' and Iran combined with "OR" Boolean in the title or abstract (Additional file 1). Also, manual search and reference tracking was used to extract additional relevant studies based on citations of the eligible articles and documents.

\section{Eligibility criteria}

There were no time restrictions. The publication language was restricted to English and Persian. All study reports, including reviews, case studies, reports, and original studies that were related to affecting factors the achieving of UHC in Iran were included in the study. Also, the abstracts of the papers presented at the seminars and conferences, news, and studies irrelevant to the study objectives were excluded from the study. All retrieved studies were screened independently by two authors (ND and MRM). Disagreements were resolved via discussion until the mutual agreement was achieved. Whenever it was not possible, a third author (SA-A) helped with reaching the consensus.

\section{Quality appraisal}

All articles after extraction from the databases using the keywords mentioned were evaluated by two authors using the Critical Appraisal Skills Program (CASP) checklist. This checklist has 10 questions; the first two questions are for screening and answered with "yes" and "no". If "yes" is the answer to the first two questions, the article will continue to be evaluated. The evaluator for each of the 8 following questions, one of the three options "yes" score 3, "no" score 1, and "cannot say" score 2, was selected. The maximum score of articles was 24 and the minimum score was 8 . Papers which scores were less than 16 were excluded from the study. Any disagreements between authors were resolved through discussing with a third investigator.

\section{Data extraction}

Data Extraction in this study was done in several steps. After removing duplicate studies, titles of all articles were reviewed and articles that were incompatible with the aims of the study were excluded. Subsequently, abstracts and full texts of the articles were studied, respectively, and studies that did not meet the inclusion criteria and had poor correlation with study aims were identified and excluded. Data were extracted according to the researcher-made data extraction form and entered into the designed table. At first, as a pilot for the data extraction form, the data of 5 papers were extracted and the deficiencies of the original form were eliminated. The whole process of the systematic review was carried out by two researchers independently and disputes were referred to as a third researcher. A list of relevant affecting factors was arrayed as the output of this phase.

\section{Phase 2: FGD and semi-structured interview}

A qualitative study was conducted to deeply explore and analyze the factors affecting the achievement of UHC in Iran. To do so, focus group discussions and semistructured interviews were held in this phase.

\section{Sampling}

By using a purposeful sampling method [41], experts in the fields of Health Policy (two people), Health Services Administration (four people), and Health Economics (two people), a top manager from the Ministry Of Health $(\mathrm{MOH})$, and two people who have practical experience in the field of UHC were selected. Experts who did not have the eligibility criteria were excluded.

\section{Including and excluding criteria for experts selecting}

- Having at least 5 year an executive experience or scientific background in the health system

- Having at least two scientific articles related to UHC

- Having at least a master's degree in the health field.

\section{Data collection}

The only FGD session was held in the department of health services management, school of health management and medical informatics, Tabriz Universities of Medical Science. FGD session was held by the coordinator and the meeting's leader to direct the discussion (the duration of the FGD was $110 \mathrm{~min}$ ). All of the 
session was recorded using a digital audio recorder and then written literally on paper so that the listed affecting factors were identified and categorized.

Also, semi-structured interviews were conducted with five experts in the field of UHC until information saturation was reached. The semi-structured interviews were conducted in the participant's office. The duration of each interview varied between 38 to $55 \mathrm{~min}$. The participants' statements were recorded by using a digital audio recorder and the research also used note-taking during the interviews. The interviews after the end of each interview were reviewed by the researchers several times and typed in Microsoft Word:2016. Data collection was continued until data saturation. In this study, after conducting four interviews, the researchers felt that the data was saturated. But for more certainty, another interview was conducted.

\section{Data analysis}

For data analysis, the content-analysis method was applied, which is a method to identify, analyze and report patterns (themes) within the text. This type of analysis is used when the theories on the subject are limited [42, 43]. Data analysis and coding processes were as follows: familiarizing with the data text, identifying and extracting the basic codes, identifying themes, reviewing and completing the identified themes, naming and defining themes, recoding and renaming some classes and themes, and ensuring the reliability of the codes.

\section{Rigour}

Responded validity was used to ensure the rigor and accuracy of the results. The participants' statements were summarized at the end of each interview and FGD session, the participants were told to confirm the accuracy of the results.

\section{Phase 3: merging factors based on framework-analysis} In this phase, the factors identified in the previous stages were merged and duplicates factors removed through the research team round table. The initial draft of categorization was refined through research team meetings.

In this phase, the health system control knob [44] was used as a framework for categorizing factors UHC in Iran. Qualitative framework analysis is a flexible data analysis method that can be used in systematic qualitative reviews $[45,46]$. The analysis process was started by studying the findings and making evidence-based inferences about organizing codes. The framework was designed and recommended in 2004 to improve the performance of countries' health systems. Control knobs are used to determine the results and outputs of health systems to which it concentrates on five dimensions including, financing, payment system, organization, regulation \& supervision, and behavior [44]. Considering that the control knobs framework was approved by the WHO and this framework considers the health systems from different points of view. One of the main reasons for deploying this framework was to identify areas of policy action to modify health systems and to improve their performance. Also, the main goals of health systems pursued by this framework (health status, customer satisfaction, and risk protection) are very similar to the dimensions of UHC. On the other hand, the intermediate goals of this framework (access, quality, and efficiency) somehow represent the goals of UHC. Another reason for using this framework is to influence the behavior of providers and consumers through populationbased interventions in the health systems, which is a significant positive point in achieving UHC. Also, we created another column in this framework to categorize some factors that were not included in the health system control knobs columns.

Categorizing were done by two researchers (ND and MR.M) using the following steps:

1. Familiarization with data (reading selected factors extracted from previous phases);

2. Generating and restate clarify themes;

3. Classifying extracted factors based on content relationship and conceptual proximity;

4. Reviewing themes, merged and categories themes into the health system control knob columns;

5. Generating refined and clear definitions for themes in the health system control knob framework.

\section{Phase 4: expert panel}

After the categorization affecting factors based on the health system control knob framework was refined through the research team, the draft version of the categorization was entered in the final phase.

The expert panel was conducted in three face-to-face sessions with the coordinator and meetings leader to control the discussion in the meantime of 65-90- min. One foreign country expert for research team consultation and poll on the categorization of factors in the framework through email and 5 local Iranian experts in UHC reviewed and discussed the content (as well as the face validity) of the health system control knob framework.

The opinions of experts were recorded by using a digital audio recorder and used by the research team to merge, add, and remove affecting factors in the health system control knob framework. Additionally, comments were obtained by the international expert were considered through the research team. 
Also, for rigor in this phases, data transferability and reliability were used from peer review, expert check, and immersed.

To observe ethical issues in this study, all experts involved in the study were asked to fill out an informed consent form to participate in the FGD, semi-structured interview, and expert panel. This study was part of a Ph.D. Thesis supported by Iran University of Medical Sciences (Thesis NO: 19114, ethical code: IR.IUMS.REC.1399.674).

\section{Results}

The phases of the study (all four phases) and their results for a better understanding of the readers are presented in Fig. 1.

\section{Results of phase 1: systematic review}

In this study, 296 articles were extracted from the databases and other sources, 108 articles were duplicates. Another 153 records were excluded by screening the title and abstract and 5 articles were removed due to lack of appropriate information and lack of reporting of the required information. Finally, 33 articles were included in the study [47-79] (Fig. 2 \& Additional file 2).

In this phase, 802 factors were extracted. Finally, after the elimination and merge of duplicate and similar factors through the research team, factors were reduced to 160 factors (Additional file 3).
Result of phase 2: FGD and semi-structured interviews FGD and semi-structured interviews were done with the participation of the 16 eligible experts. In this phase, 96 extra factors were identified. Finally, after elimination and merge similar factors, factors were reduced to 64 factors (Additional file 4).

\section{Result of phases 3 and 4: merging factors and expert panel}

In this phase, finalized affecting factors in phases 1 and 2 (160 factors through systematic review and 64 through FGD and semi-structured interviews), after elimination and merge duplicate and similar factors in round table discussion were reduced to 171 factors. Factors were classified into five dimensions related to the health system control knob framework and one another column. Finally, factors categorized in the framework axes were reviewed by expert panels and international experts and were reduced to 105 factors (Table 1 ).

In the last step, the percentage of each dimension of the health system control knob framework was calculated based on the frequency of factors. According to the results, regulation and supervision with (30\%) have highest and payment system with (7\%) has the lowest percentage (Fig. 3).

\section{Discussion}

The present study was conducted in four consecutive stages to identify the factors in the progress towards

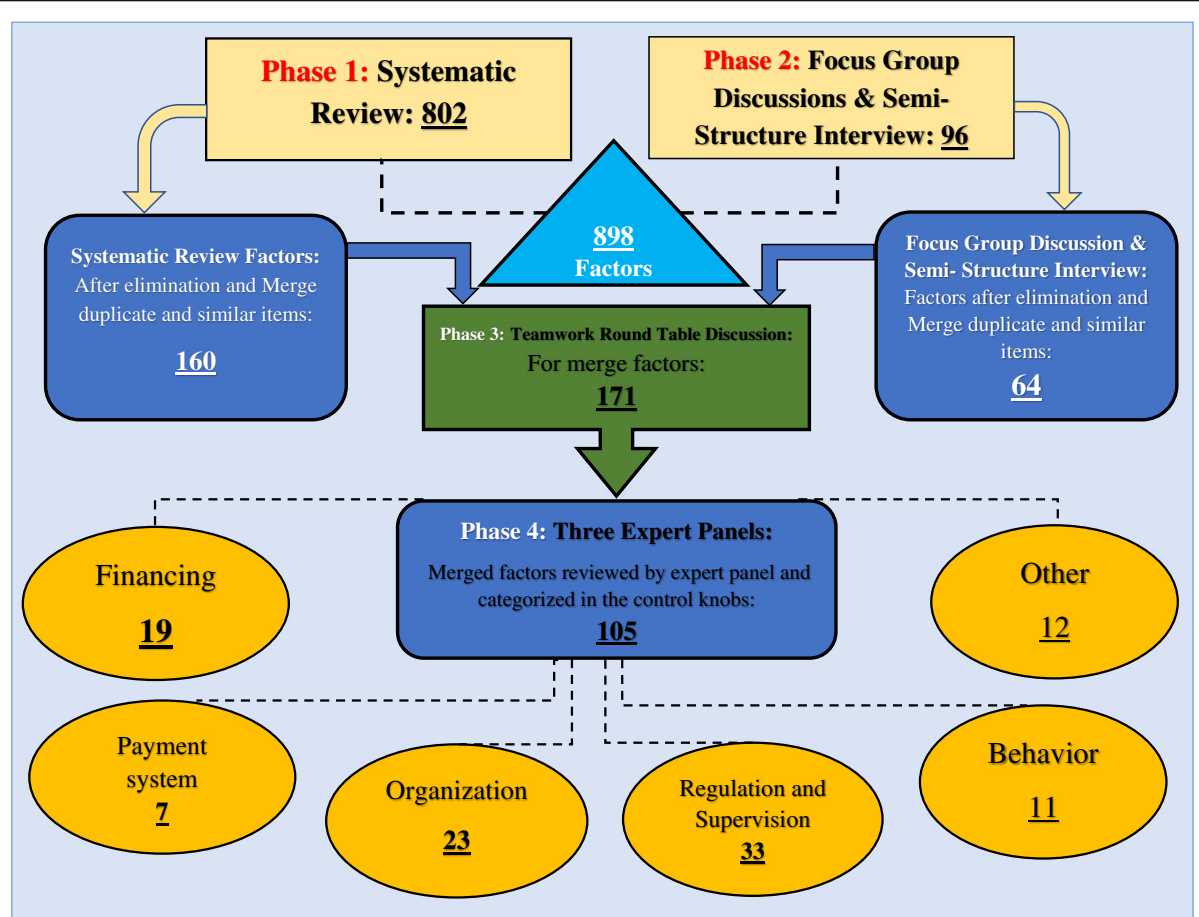

Fig. 1 The four phases (systematic review, FGD, and semi-structured interview, merging Factors, and Expert Panel) of study and their results 


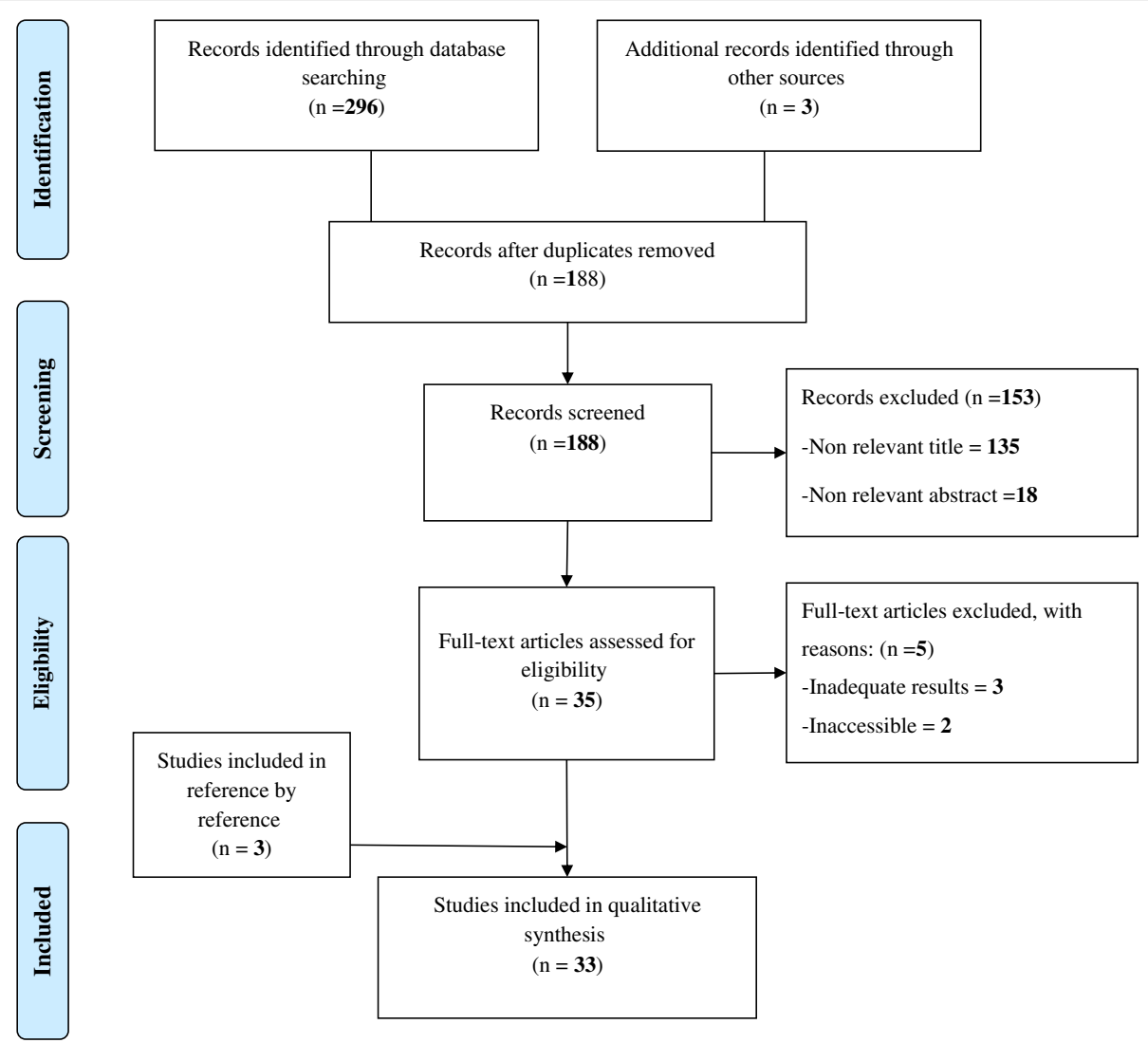

Fig. 2 Flow diagram of the searches and Inclusion process

UHC for Iran. In the systematic review stage, 160 factors and in the qualitative stage 64 factors were identified. In the third stage of the study, the factors were integrated and reduced to 171 factors. Finally, these factors through an expert panel were reduced to 105 factors and were classified within the health system's control knobs framework.

We tried to provide a comprehensive and practical exploration of factors effective in achieving UHC. In recent years, after the introduction of $\mathrm{UHC}$ by the $\mathrm{WHO}$, many international organizations and countries have tried to use such frameworks and models to achieve UHC. The WHO has also introduced some frameworks and models for this purpose [80]. One of these models presented by the WHO in 2017 was the framework of "strengthening health systems to achieve UHC". In this framework, 4 main themes (governance and financial team, integrated service delivery team, health workforce development team, and essential medicines and technologies team), 16 dimensions, and 46 indicators have been introduced [81]. Certainly, combining and integrating the strengths of these frameworks and covering the weaknesses of each of them would be very helpful. Accordingly, after the identification and integration of the factors, the research team employed the framework of control knobs to classify and present the results. Policymakers and managers can use this framework as a useful and practical tool in achieving UHC, depending on the goals of their country's health system [24].

Given the importance of "Financing", not only the WHO considers it as one of the most important requirements for reaching UHC, but also necessitates countries to review their health financing policies $[2,82,83]$. The protection against financial risks in the $\mathrm{UHC}$, an issue that is also mentioned in the framework of control knobs, is highly influenced by the financing of the country's health system. In such a way, that choosing any of the financing methods by countries can have direct and indirect effects on the implementation of UHC $[8,10$, $13,31,84,85]$. However, focusing on increasing economic growth $[86,87]$ and GDP, while allocating a proportional percentage of this GDP to the health sector are other leading elements in this case [83, 88]. Thus far, five influential factors were introduced which mostly covered the issues and aspects of financing in health systems. Due to the limitations in financing policies in different countries, these factors can act as leverage to improve financing policy-making and solve economic problems affecting this area. Some factors have played a more important role in financing the health system for 
Table 1 Categorization of extracted factors based on an expert panel on Health system Control knob in Iran

\begin{tabular}{|c|c|c|c|c|c|}
\hline Financing & $\begin{array}{l}\text { Payment } \\
\text { system }\end{array}$ & Organization & $\begin{array}{l}\text { gulation and } \\
\text { pervision }\end{array}$ & Behavior & Others \\
\hline $\begin{array}{l}\text { - Financial risk } \\
\text { protection } \\
\text { - Constraints and } \\
\text { Structural barriers in } \\
\text { Financial } \\
\text { - Methods of health } \\
\text { system financing } \\
\text { (specific tax to } \\
\text { health, Sell resources, } \\
\text {..) } \\
\text { - Sustainability of } \\
\text { financing } \\
\text { - Health expenditure } \\
\text { as \% of GDP } \\
\text { - Out of pocket } \\
\text { - Method of } \\
\text { Collecting } \\
\text { - Method of pooling } \\
\text { money } \\
\text { - Strategic } \\
\text { purchasing } \\
\text { - Health insurance } \\
\text { system } \\
\text { - International } \\
\text { assistance (donation, } \\
\text { Charity) } \\
\text { - Benefit package } \\
\text { - Economic }\end{array}$ & $\begin{array}{l}\text { - Exemption or } \\
\text { Subsidies for } \\
\text { prepayments } \\
\text { - Contribution- } \\
\text { based on pay- } \\
\text { ment capacity } \\
\text { - Prepayment } \\
\text { mechanisms } \\
\text { - Payment } \\
\text { systems } \\
\text { - Information } \\
\text { and interaction } \\
\text { of insurance } \\
\text { deductions for } \\
\text { health } \\
\text { - Informal } \\
\text { payments } \\
\text { - Deductible }\end{array}$ & $\begin{array}{l}\text { - Health system Leadership } \\
\text { - Management in the health } \\
\text { system (Resource } \\
\text { management, human } \\
\text { resources, Change } \\
\text { management, ...) } \\
\text { - Health infrastructure } \\
\text { (technology, information } \\
\text { system, ...) } \\
\text { - The capacity of formulation } \\
\text { and implementation of } \\
\text { health policies } \\
\text { - Structural and functional } \\
\text { reforms } \\
\text { - Distribution of health } \\
\text { provider } \\
\text { - Decentralization in } \\
\text { decision-making } \\
\text { - Non-governmental organi- } \\
\text { zations (Civil society organi- } \\
\text { zations: Private sector, NGOs } \\
\text { and charities) participant } \\
\text { - Integration or Fragmented } \\
\text { degree of the health system } \\
\text { - Equity in the distribution of } \\
\text { health system resources } \\
\text { - Equity in access to health } \\
\text { services }\end{array}$ & $\begin{array}{l}\text { - Health system efficiency } \\
\text { - Government } \\
\text { commitment } \\
\text { - Have Legal commitment } \\
\text { - Problems of law } \\
\text { - Political commitment } \\
\text { and not having politically } \\
\text { look } \\
\text { - Good governance } \\
\text { - Hasty policy } \\
\text { implementation by } \\
\text { politicians } \\
\text { - Conflict of interest } \\
\text { - Quality of health care } \\
\text { services } \\
\text { - Supporting revision } \\
\text { projects and national } \\
\text { health indicators } \\
\text { development. } \\
\text { - Focus on, villagers, } \\
\text { nomads, less populated } \\
\text { cities poor, disadvantaged } \\
\text { and marginalized groups } \\
\text { - Family Physician } \\
\text { Program } \\
\text { - Referral system } \\
\text { - Strengthen the central } \\
\text { government's Ministry of }\end{array}$ & $\begin{array}{l}\text { - Health promotion } \\
\text { and education } \\
\text { - Culture-building } \\
\text { - Empowering } \\
\text { community } \\
\text { - Perceived behavioral } \\
\text { control } \\
\text { - Issues of urbanization } \\
\text { - Absence of } \\
\text { obligation for health } \\
\text { providers to contract } \\
\text { with insurance } \\
\text { organizations } \\
\text { - Negligence of social } \\
\text { factors } \\
\text { - Social acceptability of } \\
\text { health service } \\
\text { - public participation } \\
\text { in health promotions } \\
\text { programs } \\
\text { - Creating an incentive } \\
\text { mechanism for } \\
\text { behavior change } \\
\text { - The pattern of health } \\
\text { service utilization }\end{array}$ & $\begin{array}{l}\text { - Poverty } \\
\text { - Reviewing other } \\
\text { countries experiences } \\
\text { - The unemployment } \\
\text { rate in the country } \\
\text { - Active primary } \\
\text { health care } \\
\text { - International } \\
\text { relationship } \\
\text { - Health status of } \\
\text { health indicators } \\
\text { - Prevention and } \\
\text { control plans of non- } \\
\text { communicable and } \\
\text { communicable } \\
\text { diseases } \\
\text { - Demographic and } \\
\text { epidemiologic } \\
\text { transitions } \\
\text { - Provide community- } \\
\text { based services } \\
\text { - Health system } \\
\text { service preferences } \\
\text { (prevention-oriented } \\
\text { or treatment-oriented) } \\
\text { - Disease Pattern } \\
\text { - Knowledge } \\
\text { translation }\end{array}$ \\
\hline
\end{tabular}

vulnerability in

health

- International

sanctions

- Costs Control

- Health service

tariffs

- Per capita income

- The economic

growth rate

- Inflation rate

- Use of Appropriate technology in the health system

- The necessity for grading health service centers and giving the insured sufficient notice of this grading

- Bureaucratic obstacles

- Systematic perspective

- Inter and intra-sectoral

collaboration

- teamwork

- Competency and Stability

Management

- Policies and programs

belonging to persons

- Effective Services Coverage

- Priority health services

- Overlaps in healthcare

provision

- Involving all relevant stakeholders in the policymaking process
Health

- Control demands

- Regular transparency of revenues, expenditures, and activities

- Implement the rules of the World Health

Organization

- Administrative and employment regulation - Regulate the market of medical equipment

- Reviewing job classification schemes according to the needs of the health system.

- Electronic Health Record (EHR)

- Overlap in population

coverage

- The dual practice of physician and another health workforce

- Competitive space between the providers.

- Policy dynamism

- Use of clinical guidelines

and standards

- Performance of Supreme Council of Insurance

- oversight parliament

- Supervision by the ministry and the

university

- The presence of specialists in public hospitals

- Plan to support the 
Table 1 Categorization of extracted factors based on an expert panel on Health system Control knob in Iran (Continued)

\begin{tabular}{|c|c|c|c|c|}
\hline Financing & $\begin{array}{l}\text { Payment } \\
\text { system }\end{array}$ & Organization & $\begin{array}{l}\text { Regulation and } \\
\text { Supervision }\end{array}$ & Others \\
\hline & & & $\begin{array}{l}\text { retention of physicians in } \\
\text { underserved areas } \\
\text { - Assessment and } \\
\text { accreditation of the health } \\
\text { system performance } \\
\text { - Evidence-based } \\
\text { policymaking }\end{array}$ & \\
\hline
\end{tabular}

achieving UHC, such as out-of-pocket payments, type of financing in the health system, high medical tariffs, sustainability of financing, international sanctions, service packages, strategic purchases, excessive inflation, and Health insurance system. A study in Lao PDR showed that to achieve UHC, the country needs health insurance and public awareness of health insurance and its benefits [89]. Also, Studies in LMICs show that high OOP payments can create a major gap in countries for Achieving UHC [90-94]. On the way to UHC, LMICs Governments require adequate and sustainable funding [91, 95, 96]. Commonly, governments use a combination of health financing mechanisms for financing, while LMICs rely more on OOP payments, social health insurance, international donor, and allocations from national budgets $[95,96]$. A study conducted in seven LMICs (Costa Rica, Georgia, India, Malawi, Nigeria, Tanzania, and Thailand) showed that the health system financing through taxes and compulsory health insurance is very important to improve financial protection by reducing OOP payments [97]. also, capacity constraints in purchasing organizations are another problem that needs to be addressed in LMICs [97].

The "Payment System" is another health system's control knob. Despite having fewer factors categorized within this dimension, the payment system plays a distinct role regarding UHC. The importance of this dimension best highlights when we consider its direct impact on three goals of UHC including, financial protection, population coverage, and service coverage. Also, it can affect justice in access to health services and make the path clear or uneven to UHC for every country [98100]. It should be noted that the payment system is affected by other control knobs such as financing, organizing and legislation, and supervision, and is adjusted according to these knobs. This can make this control knob more powerful and turn it into an executive arm (stakeholder control system) among the control knobs. Successful implementation and monitoring of the implementation of this control knob will be crucial for any country to reach UHC $[101,102]$. The Philippines has shifted the payment mechanism away from fee for

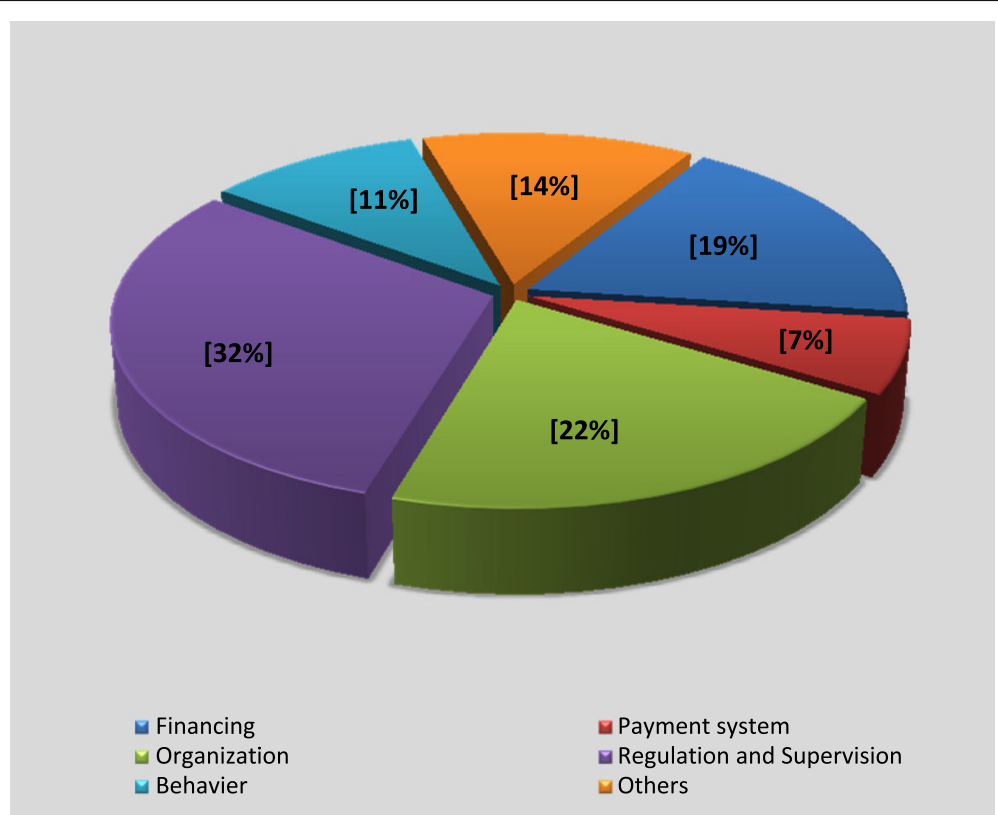

Fig. 3 The percentage of influential factors for achieving universal health coverage in Iran based on health system control knob framework 
services to case-based payments, which can be chivied to the goals such as; streamlining claims payment, increasing transparency, optimizing health care delivery, and ultimately achieving greater financial support [103, 104].

Proper service coverage for the people of any country requires due organization of the health system to pave the way for achieving UHC. The control knob of "Organization", with 23 factors, plays a decisive and powerful role in achieving UHC. Paying attention to the characteristics of this knob, enables policy-makers and managers to establish internal and external strong relationships, manage the resources effectively, and provide a proper distribution of resources based on the capacity and infrastructure of each society that can bring the country one step closer to UHC [51, 59, 105-108]. Furthermore, through a systematic perspective on the health system, this dimension can lead to the unity of the health system, and by eliminating organizational and managerial barriers, it provides fair access to health services for people [109-111]. In LMICs, this dimension takes a double-folded value, where, the countries face severe shortages in health resources [58, 112-116].

The study indicated that the most number of identified factors were within "the Regulation and Supervision" control knob (33 factors). As mentioned, UHC is a new philosophy and approach, making major changes in most parts of the health system and other sectors related to the health system. Therefore, a coherent and effective regulation and supervision system must be established at the beginning of the path to achieving this goal. Adequate supervision can ensure a legal context to strengthen the health system which results in due employment of policies and regulations to reach UHC [117-119]. As mentioned before, there are fundamental problems and deficiencies in LMICs in terms of weak legislation and regulatory structures that demand to strengthen this knob through effectively dealing with the factors introduced during the current study. Another critical point is the great dependence of this knob on the context of the health system which contains the political and administrative structure of the country, too. This is because of various laws and miscellaneous methods of monitoring that are developed and applied by external regulators. Therefore, it necessitates paying a sufficient amount for inter-sectoral partnerships and government commitment in this dimension. Also, the case studies in LMICs highlighted the critical roles of political leadership, political commitment, and good governance in pursuing and sustaining UHC policies [97, 120-123]. Lack of political commitment and commitment to UHC was identified as a common challenge among African countries [124]. A study conducted in 11 different countries (Bangladesh, Brazil, Ethiopia, France, Ghana, Indonesia, Japan, Peru, Thailand, Turkey, and Vietnam) with different UHC status showed that countries must have both of the necessary technical and political knowledge to move towards UHC [125].

The last control knob in the framework "behavior". This knob is associated with all stakeholders in the health system and is effective in regulating the behavior of the provider, recipient, and buyer of the service. Culture building and attracting public participation are two crucial elements of this dimension [126-128] in achieving the goals of the health system. People's participation can provide a constant movement towards UHC [119, 129]. This knob, by coordinating stakeholders and involving them, can act as a facilitator and accelerator bringing the country closer to the UHC in less time. As mentioned, community participation has a distinct role regarding societies' health behaviors, therefore, the concentration of the health system should be the promotion of social culture and public health. The most beneficial measures could be the proper use of health resources, promoting health behaviors, improving health literacy, promoting the culture of self-care, and empowering people to participate in strengthening and supporting the health system.

In a study entitled "the challenges and opportunities to achieving UHC in Nepal", the factors such as using Constitutional provision, global support, and progress on the health insurance act, decentralization of health service to the grass-roots level, were introduced as an opportunity to move towards UHC. Also, the support of stakeholders, a sense of national priority and international support, Government stewardship, the political commitment under the changing political context, and fair contribution and distribution of resources by appropriate health financing modality as facilitators of the country's health system would boost the speed of achieving UHC in Nepal [130]. In another study in China, factors such as social security system, population, economic development, and education have been introduced as contextual factors for achieving UHC [131]. Moreover, factors such as lack of capacity service, socioeconomic disparities in the access to and utilization of hospital-level health services and costs, out-of-pocket spending, the low-income context in the country, harness the political commitment, and geographical barriers have been introduced factors for achieving UHC in Ethiopia [132].

In the present study, some factors that could not be classified in the control knobs were categorized in a separate column and were discussed between experts. Items such as poverty, review of other countries' experiences, unemployment rate, active delivery of primary health care, the status of the country's health indicators, demographic and epidemiological transition, knowledge transfer, community-based service delivery, health system service preferences (prevention-oriented or treatment- 
oriented), diseases pattern and communicable and noncommunicable disease prevention programs, were categorized in this column. Given the importance of these factors, the researchers did not rule out these cases. Therefore, it seems that these cases can play a complementary role to other control knobs.

\section{Limitation}

One of the limitations of the present study was the participation of only Iranian experts and also the systematic review which was limited to research conducted in Iran, which could reduce the generalizability of the results. To increase the generalizability and validity of the study results, the researchers tried to identify and categorize the factors using several different methods (systematic review, a qualitative study including focused group discussion and semi-structured interview, expert panel, and teamwork). Study design in this way can increase the usability of the study results and their validity. Also, to increase the generalizability of the results, in this study, the framework of the control knobs of the WHO has been used to classify the factors. This feature of the study can also allow other countries to benefit from the results of the study.

\section{Conclusion}

The results of the study show that in achieving UHC, countries need to identify the influencing factors and prioritize these factors following their internal capacities. Categorizing the influencing factors in achieving UHC in the form of an approved framework such as control knobs can give countries the advantage of having a comprehensive analysis of their health system. Therefore, considering these factors, countries can identify their strengths and weaknesses in this path and design the necessary and planned measures in this direction to accelerate the achievement of UHC.

This study, by presenting the factors and classifying them in the framework of control knobs, facilitates the recognition of these factors according to their nature and the main area for countries and provides the basis for measures to correct and cover weaknesses in the health system of countries.

\section{Abbreviations \\ UHC: Universal Health Coverage; OOP: Out Of Pocket; LMICs: Low and Middle-Income Countries; HICs: High-Income Countries; WHO: World Health Organization; WB: World Bank; FGD: Focus Group Discussion; CASP: Critical Appraisal Skills Program; LIC: Low-Income Countries}

\section{Supplementary Information}

The online version contains supplementary material available at https://doi. org/10.1186/s12913-021-06673-0.

Additional file 1. Appendix 1-Complete search strategies for databases.
Additional file 2. Appendix 2-Characteristics of extracted studies with consideration to affecting factors to achieving UHC in Iran.

Additional file 3. Appendix 3- Identification affecting factors to achieving UHC trough systematic review in Iran.

Additional file 4. Appendix 4- Identification affecting factors to achieving UHC trough FGD and semi-structured interviews in Iran.

Additional file 5. Appendix 5- List of excluded studies.

Additional file 6. Appendix 6- Quality assessment of the study.

\section{Acknowledgements}

We are very grateful to Experts for contribution and time and invaluable comments.

\section{Authors' contributions}

N.D \& MR.M collected, reviewed papers, analyzed and prepared the Figs. S.AA \& N. D contributed in designing, analyzing and drafting the paper. H. P \& MR. M contributed in categorizing the factors and reviewing and N. D \& H. P \& S.A-A Contributed in analyzing and editing the paper. All authors have contributed significantly, and that all authors read and approved the final version of the manuscript.

\section{Funding}

This study was part of a Ph.D. Thesis supported by Iran University of Medical Sciences (Thesis NO: 19114). The funding body played no role in the design of the study, analysis and interpretation of data, or in writing the manuscript.

Availability of data and materials

All data generated or analyzed during this study are included in this published article in Additional files 1 and 2.

\section{Declarations}

Ethics approval and consent to participate

The protocol for the research project has been approved by the ethics committee at IUMS which is in compliance with the Helsinki Declaration and all participants gave informed consent before inclusion in the study. (Ethical approval code: IR.IUMS.REC.1399.674)

\section{Consent for publication}

Not applicable.

\section{Competing interests}

The authors state they have no conflicts of interest to declare.

\section{Author details}

'Department of Health Services Management, School of Health Management and Information Sciences, Iran University of Medical Sciences, Tehran, Iran.

${ }^{2}$ Tabriz Health Services Management Research Center, Health Management and Safety Promotion Research Institute, Tabriz University of Medical Sciences, Tabriz, Iran.

Received: 27 January 2021 Accepted: 23 June 2021

Published online: 22 July 2021

\section{References}

1. Evans DB, Saksena P, Elovainio R, Boerma T. Measuring progress towards universal coverage. Geneva: World Health Organization; 2012.

2. Organization $\mathbf{W H}$. The world health report 2000: health systems: improving performance: World Health Organization; 2000.

3. Maeda A, Araujo E, Cashin C, Harris J, Ikegami N, Reich MR. Universal health coverage for inclusive and sustainable development: a synthesis of 11 country case studies: World Bank publications; 2014.

4. Obare V, Brolan CE, Hill PS. Indicators for universal health coverage: can Kenya comply with the proposed post-2015 monitoring recommendations? Int J Equity Health. 2014;13(1):123.

5. Xu Y, Huang C, Colón-Ramos U: Moving toward universal health coverage (UHC) to achieve inclusive and sustainable health development: three essential strategies drawn from Asian experience: comment on'Improving 
the World's health through the Post-2015 development agenda: perspectives from Rwanda'. 2015.

6. Pannarunothai S, Patmasiriwat D, Srithamrongsawat S. Universal health coverage in Thailand: ideas for reform and policy struggling. Health Policy. 2004;68(1):17-30

7. Supachutikul A. Situation analysis on health insurance and future development: Thailand Health Research Institute; 1996.

8. Organization $\mathrm{WH}$. Tracking universal health coverage: first global monitoring report: World Health Organization; 2015.

9. Savedoff WD, de Ferranti D, Smith AL, Fan V. Political and economic aspects of the transition to universal health coverage. Lancet. 2012;380(9845):92432.

10. Evans DB, Etienne C. Health systems financing and the path to universal coverage. Bull World Health Organ. 2010;88(6):402-3.

11. Lagomarsino G, Garabrant A, Adyas A, Muga R, Otoo N. Moving towards universal health coverage: health insurance reforms in nine developing countries in Africa and Asia. Lancet. 2012;380(9845):933-43.

12. Bredenkamp C, Evans T, Lagrada L, Langenbrunner J, Nachuk S, Palu T. Emerging challenges in implementing universal health coverage in Asia. Soc Sci Med. 2015;145:243-8.

13. Garrett $L$, Chowdhury AMR, Pablos-Méndez A. All for universal health coverage. Lancet. 2009;374(9697):1294-9.

14. Brandford DeLong J. Contours of the world economy 1-2030 AD: essays in macro-economic history. New York: Oxford University Press; 2007.

15. Campbell J, Buchan J, Cometto G, David B, Dussault G, Fogstad H, et al. Human resources for health and universal health coverage: fostering equity and effective coverage. Bull World Health Organ. 2013;91(11):853-63.

16. Almaspoor Khangah H, Jannati A, Imani A, Salimlar S, Derakhshani N, Raef B. Comparing the health care system of Iran with various countries. Health Scope. 2017;6(1):e34459.

17. Mehrdad R. Health system in Iran. JMAJ. 2009;52(1):69-73.

18. Arani AA, Atashbar T, Antoun J, Bossert T. Iran's health reform plan: measuring changes in equity indices. Iran J Public Health. 2018;47(3):390.

19. Olyaeemanesh A, Behzadifar M, Mousavinejhad N, Behzadifar M, Heydarvand S, Azari S, et al. Iran's health system transformation plan: a SWOT analysis. Med J Islam Repub Iran. 2018;32:39.

20. Ahmadnezhad E, Murphy A, Alvandi R, Abdi Z. The impact of health reform in Iran on catastrophic health expenditures: equity and policy implications. Int J Health Plann Manag. 2019;34(4):e1833-45.

21. Asadi-Lari M, Sayyari A, Akbari M, Gray D. Public health improvement in Iran-lessons from the last 20 years. Public Health. 2004;118(6):395-402.

22. Bahadori M, Ravangard R, Alimohammadzadeh K, Hosseini SM. Plan and road map for health reform in Iran. Bmj. 2015;351.

23. Mehrolhassani MH, Jafari Sirizi M, Poorhoseini SS, Yazdi Feyzabadi V. The challenges of implementing family physician and rural insurance policies in Kerman province, Iran: a qualitative study. Health Dev J. 2012;1(3):193-206.

24. Tabrizi JS, Pourasghar F, Gholamzadeh Nikjoo R. Status of Iran's primary health care system in terms of health systems control knobs: a review article. Iran J Public Health. 2017:46(9):1156-66.

25. Doshmangir L, Rashidian A, Kouhi F, Gordeev VS. Setting health care services tariffs in Iran: half a century quest for a window of opportunity. Int J Equity Health. 2020;19(1):112.

26. Dehghani M, Mesgarpour B, Akhondzadeh S, Azami-Aghdash S, Ferdousi R. How the US sanctions are affecting the Health Research system in Iran? Arch Iran Med. 2021;24(2):101-6.

27. Hosseini SA. Impact of sanctions on procurement of medicine and medical devices in Iran; a technical response. Arch Iran Med. 2013;16(12):736-8.

28. Çiçeklioğlu M, Öcek ZA, Turk M, Taner \$̧. The influence of a market-oriented primary care reform on family physicians' working conditions: a qualitative study in Turkey. Eur J Gen Pract. 2015;21(2):1-6.

29. Evans T, Chowdhury A, Evans D, Fidler A, Lindelow M, Mills A, et al. Thailand's universal coverage scheme: achievements and challenges. Independent Assess First. 2012;10:2001-10.

30. Mulupi S, Kirigia D, Chuma J. Community perceptions of health insurance and their preferred design features: implications for the design of universal health coverage reforms in Kenya. BMC Health Serv Res. 2013;13(1):474.

31. Organization $\mathbf{W H}$. Increasing access to health workers in remote and rural areas through improved retention: global policy recommendations: World Health Organization; 2010.

32. Carrin G, James C, Organization WH: Reaching universal coverage via social health insurance: key design features in the transition period. 2004.
33. Borgonovi $E$, Compagni A. Sustaining universal health coverage: the interaction of social, political, and economic sustainability. Value Health. 2013;16(1):S34-8.

34. Van Minh H, Pocock NS, Chaiyakunapruk N, Chhorvann C, Duc HA, Hanvoravongchai P, et al. III10 DEL-P, Ng12 N, Phaholyothin13 N: Progress toward universal health coverage in ASEAN. Glob Health Action. 2014; 7(25856): 1 .

35. Marten R, Mclntyre D, Travassos C, Shishkin S, Longde W, Reddy S, et al. An assessment of progress towards universal health coverage in Brazil, Russia, India, China, and South Africa (BRICS). Lancet. 2014;384(9960):2164-71.

36. Yasar GY, Ugurluoglu E. Can Turkey's general health insurance system achieve universal coverage? Int J Health Plann Manag. 2011;26(3):282-95.

37. Aguilera X, Castillo-Laborde C, Najera-De Ferrari M, Delgado I, Ibañez C. Monitoring and evaluating progress towards universal health coverage in Chile. PLoS Med. 2014;11(9):e1001676.

38. Devadasan N, Ghosh S, Nandraj S, Sundararaman T. Monitoring and evaluating progress towards universal health coverage in India. PLoS Med. 2014;11(9):e1001697.

39. Guinto RLLR, Curran UZ, Suphanchaimat R, Pocock NS. Universal health coverage in 'one ASEAN': are migrants included? Glob Health Action. 2015; $8(1): 25749$.

40. Liberati A, Altman DG, Tetzlaff J, Mulrow C, Gøtzsche PC, loannidis JP, et al. The PRISMA statement for reporting systematic reviews and meta-analyses of studies that evaluate health care interventions: explanation and elaboration. PLoS Med. 2009;6(7):e1000100.

41. Palinkas LA, Horwitz SM, Green CA, Wisdom JP, Duan N, Hoagwood K. Purposeful sampling for qualitative data collection and analysis in mixed method implementation research. Admin Pol Ment Health. 2015;42(5):533-44.

42. Grbich C. Qualitative data analysis: an introduction: sage; 2012.

43. Pope C, Ziebland S, Mays N. Qualitative research in health care. Analysing qualitative data. Bmj. 2000;320(7227):114-6.

44. Roberts M, Hsiao W, Berman P, Reich M. Getting health reform right: a guide to improving performance and equity: Oxford university press; 2003.

45. Furber C. Framework analysis: a method for analysing qualitative data. Afr J Midwifery Womens Health. 2010;4(2):97-100.

46. Gale NK, Heath G, Cameron E, Rashid S, Redwood S. Using the framework method for the analysis of qualitative data in multi-disciplinary health research. BMC Med Res Methodol. 2013;13(1):1-8.

47. Peykari N, Hashemi H, Dinarvand R, Haji-Aghajani M, Malekzadeh R, Sadrolsadat A, et al. National action plan for non-communicable diseases prevention and control in Iran; a response to emerging epidemic. J Diab Metab Disord. 2017;16(1):3.

48. Universal health coverage in Iran. Observation report of Islamic republic of Iran's National Institute of Health Research. 2014.

49. Ibrahimipour H, Maleki MR, Brown R, Gohari M, Karimi I, Dehnavieh R. A qualitative study of the difficulties in reaching sustainable universal health insurance coverage in Iran. Health Policy Plan. 2011;26(6):485-95.

50. Piroozi B, Moradi G, Nouri B, Bolbanabad AM, Safari H. Catastrophic health expenditure after the implementation of health sector evolution plan: a case study in the west of Iran. Int J Health Policy Manag. 2016;5(7):417.

51. Mehrolhassani M, Najafi B, Yazdi Feyzabadi V, Abolhallaje M, Ramezanian M, Dehnavieh $R$, et al. A review of the health financing policies towards universal health coverage in Iran. Iran J Epidemiol. 2017;12(5):74-84.

52. Mousavi SM, Sadeghifar J. Universal health coverage in Iran. Lancet Glob Health. 2016:4(5):e305-6.

53. Moghadam MN, Banshi M, Javar MA, Amiresmaili M, Ganjavi S. Iranian household financial protection against catastrophic health care expenditures. Iran J Public Health. 2012;41(9):62.

54. Marnani AB, Teymourzadeh E, Bahadori M, Ravangard R, Pour JS. Challenges of a large health insurance organization in Iran: a qualitative study. Int J Collab Res Intern Med Public Health. 2012;4(6):1050-62.

55. Abdellah $Y$, Pourfathollah AA, Eslama $H$, Raouf $M$. The role of access to affordable and quality assured blood and blood products for achieving universal health coverage. Scientific J Iran Blood Transfus Organ. 2018;15(4):235-8.

56. Bakhtiari A, Takian DA, Sayari DA, Bairami F, Sadeghtabrizi DJ, Mohammadi $A$, et al. Design and deployment of health complexes in line with universal health coverage by focusing on the marginalized population in Tabriz. Iran Teb va Tazkiyeh. 2017;25(4):213-32.

57. Alinia C, Lahijan JD. Moving toward universal health coverage: four decades of experience from the Iranian health system. ClinicoEcon Outcomes Res. 2019;11:651. 
58. Ehsani-Chimeh E, Sajadi HS, Majdzadeh R. Iran towards universal health coverage: the role of human resources for health. Med J Islam Repub Iran. 2018;32:100

59. Zalani GS, Khalilnezhad R, Mirbahaeddin E, Shokri A, Kashkalani T, Bayat M. Human resources for health strategies: the way to achieve universal health coverage in the Islamic Republic of Iran. East Mediterr Health J. 2018;24(09): $846-54$

60. ER SH. Health system reform plan in Iran: approaching universal health coverage. Hakim Res J. 2016;18(4):329-35.

61. Riazi-Isfahani S, Moradi-Lakeh M, Mafimoradi S, Majdzadeh R. Universal health coverage in Iran: health-related intersectoral actions. Med J Islam Repub Iran. 2018;32:132.

62. Koohpayehzadeh J, Kassaeian SS. Determining and prioritizing indicators of public health coverage in Iran: a qualitative study. Koomesh. 2018;20(2):410-6.

63. Letafat M, Beyranvand T, Aryankhesal A, Behzadifar M, Behzadifar M. Universal health coverage (UHC) in Iran. Iran J Public Health. 2018;47(7): 1061-2.

64. Doshmangir L, Yousefi M, Hasanpoor E, Eshtiagh B, Haghparast-Bidgoli $H$. Determinants of catastrophic health expenditures in Iran: a systematic review and meta-analysis. Cost Eff Resour Alloc. 2020;18:17.

65. Doshmangir L, Bazyar M, Majdzadeh R, Takian A. So near, so far: four decades of health policy reforms in Iran, Achievements and Challenges. Arch Iran Med. 2019;22(10):592-605.

66. Doshmangir L, Moshiri E, Mostafavi H, Sakha MA, Assan A. Policy analysis of the Iranian health transformation plan in primary healthcare. BMC Health Serv Res. 2019;19(1):670.

67. Maleki MR, Ibrahimipour H, Karimi I, Gohari MR. Sustainable universal health insurance coverage barriers in Iran: 2007. Payesh (Health Monitor). 2010;9(2): 173-87.

68. Meskarpour Amiri M, Teymourzadeh E, Ravangard R, Bahadori M. Health informal payments and their main determinants: the case of Iran. Proc Singapore Healthcare. 2019;1:1.

69. Kabir MJ, Heidari A, Jafari N, Honarvar MR, Behnampour N, Mirkarim SK. Developing basic health services packages: defining a prioritization of effectiveness criteria. Int J Healthc Manage. 2019;1:1.

70. Naghdi S, Moradi T, Tavangar F, Bahrami G, Shahboulaghi M, Ghiasvand H. The barriers to achieve financial protection in Iranian health system: a qualitative study in a developing country. Ethiop J Health Sci. 2017;27(5): 491-500.

71. Nosratnejad S, Rashidian A, Jafari N, Ahari AM. Universal health insurance and the reasons of not coverage in Iran: secondary analysis of a National Household Survey. Depiction Health. 2019;2(4):28-35.

72. Dehnavieh R, Haghdoost AA, Majdzadeh R, Noorihekmat S, Ravaghi H, Mehrolhasani $\mathrm{MH}$, et al. Quality of health services of the islamic republic of Iran: status, barriers and improvement strategies. Iran J Epidemiol. 2018; 13(5):1-12.

73. Sajadi HS, Majdzadeh R. From primary health care to universal health coverage in the Islamic Republic of Iran: a journey of four decades. Arch Iran Med. 2019;22(5):262-8

74. Sajadi HS, Ehsani-Chimeh E, Majdzadeh R. Response to: letter to the editor "universal health coverage in Iran: where we stand and how we can move forward". Med J Islam Repub Iran. 2019;33:106.

75. Soltani S, Takian A, Akbari Sari A, Majdzadeh R, Kamali M. Financial barriers to access to health Services for Adult People with disability in Iran: the challenges for universal health coverage. Iran J Public Health. 2019;48(3):508-15.

76. Abdi Z, Yazdizadeh B, Ahmadnezhad E, Rahimi M, Majdzadeh R. Universal health coverage in Iran: what kind of knowledge is needed to achieve the goals? Med J Islam Repub Iran. 2019;33:65.

77. Behzadifar M, Saran M, Behzadifar M, Martini M, Bragazzi NL. The 'health transformation Plan'in Iran: a policy to achieve universal health coverage in slums and informal settlement areas. Int J Health Plann Manag. 2020.

78. Doshmangir L, Bazyar M, Rashidian A, Gordeev VS. Iran health insurance system in transition: equity concerns and steps to achieve universal health coverage. Int J Equity Health. 2021;20(1):1-14.

79. Bastani P, Hakimzadeh SM, Teymourzadeh E, Nouhi M. Universal health coverage under the joint comprehensive plan of Action's sanctions: strategic purchasing approach in the Iranian health system. Health Promot Int. 2020.

80. Mikkelsen-Lopez I, Wyss K, de Savigny D. An approach to addressing governance from a health system framework perspective. BMC Int Health Hum Rights. 2011;11(1):13.
81. World Health Organization ROftEM. Strengthening health systems towards universal health coverage : an introduction to the department of health system development. Cairo: World Health Organization. Regional Office for the Eastern Mediterranean; 2017.

82. Mohammadibakhsh R, Aryankhesal A, Jafari M, Damari B. Family physician model in the health system of selected countries: a comparative study summary. J Educ Health Promot. 2020;9:160.

83. Derakhshani N, Doshmangir L, Ahmadi A, Fakhri A, Sadeghi-Bazargani H, Gordeev VS. Monitoring process barriers and enablers towards universal health coverage within the sustainable development goals: a systematic review and content analysis. Clinicoecon Outcomes Res. 2020;12:459-72.

84. Saksena P, Hsu J, Evans DB. Financial risk protection and universal health coverage: evidence and measurement challenges. PLoS Med. 2014;11(9): e1001701.

85. Saadati M, Rezapour R, Derakhshani N, Naghshi M. Comparative study of fair financing in the health insurance; 2017.

86. Atun R, De Andrade LOM, Almeida G, Cotlear D, Dmytraczenko T, Frenz P, et al. Health-system reform and universal health coverage in Latin America. Lancet. 2015;385(9974):1230-47.

87. Damrongplasit K, Melnick G. Funding, coverage, and access under Thailand's universal health insurance program: an update after ten years. Appl Health Econ Health Policy. 2015;13(2):157-66.

88. Van Minh H, Pocock NS, Chaiyakunapruk N, Chhorvann C, Duc HA, Hanvoravongchai $P$, et al. Progress toward universal health coverage in ASEAN. Glob Health Action. 2014;7(1):25856.

89. Chaleunvong K, Phoummalaysith B, Phonvixay B, Sychareun V, Durham J, Essink DR. Factors affecting knowledge of National Health Insurance Policy among out-patients in Lao PDR: an exit interview study. Glob Health Action. 2020;13(sup2):1791414

90. Fried ST, Khurshid A, Tarlton D, Webb D, Gloss S, Paz C, et al. Universal health coverage: necessary but not sufficient. Reprod Health Matters. 2013; 21(42):50-60.

91. Chu A, Kwon S, Cowley P. Health financing reforms for moving towards universal health coverage in the western pacific region. Health Syst Reform. 2019;5(1):32-47.

92. De Allegri M, Sauerborn R, Kouyaté B, Flessa S. Community health insurance in sub-Saharan Africa: what operational difficulties hamper its successful development? Tropical Med Int Health. 2009;14(5):586-96.

93. Adewole DA, Akanbi SA, Osungbade KO, Bello S. Expanding health insurance scheme in the informal sector in Nigeria: awareness as a potential demand-side tool. Pan Afr Med J. 2017;27.

94. Adewole DA, Adebayo AM, Udeh El, Shaahu VN, Dairo MD. Payment for health care and perception of the national health insurance scheme in a rural area in Southwest Nigeria. Am J Trop Med Hygiene. 2015;93(3):648-54.

95. Lin V, Leung G, Carter B. Asia-Pacific countries moving toward universal health coverage. Health Syst Reform. 2019;5(1):1-6.

96. Kutzin J. Anything goes on the path to universal health coverage? No. Bull World Health Organ. 2012;90:867-8.

97. McIntyre D, Ranson MK, Aulakh BK, Honda A: Promoting universal financial protection: evidence from seven low-and middle-income countries on factors facilitating or hindering progress. Health Res Policy Syst 2013, 11(1): $1-10$.

98. Cheng S-H, Chen C-C, Tsai S-L. The impacts of DRG-based payments on health care provider behaviors under a universal coverage system: a population-based study. Health Policy. 2012;107(2-3):202-8.

99. Garchitorena A, Miller AC, Cordier LF, Ramananjato R, Rabeza VR, Murray M, et al. In Madagascar, use of health care services increased when fees were removed: lessons for universal health coverage. Health Aff. 2017;36(8):1443-51.

100. Doshmangir L, Sajadi HS, Ghiasipour M, Aboutorabi A, Gordeev VS. Informal payments for inpatient health care in post-health transformation plan period: evidence from Iran. BMC Public Health. 2020;20:1-14.

101. Tang S, Tao J, Bekedam H. Controlling cost escalation of healthcare: making universal health coverage sustainable in China. BMC Public Health. 2012; 2012:58.

102. Asaria M, Ali S, Doran T, Ferguson B, Fleetcroft R, Goddard M, et al. How a universal health system reduces inequalities: lessons from England. J Epidemiol Community Health. 2016;70(7):637-43.

103. Tobe M, Stickley A, del Rosario Jr RB, Shibuya K. Out-of-pocket medical expenses for inpatient care among beneficiaries of the National Health Insurance Program in the Philippines. Health Policy Plan. 2013;28(5):536-48. 
104. Dalmacion GV, Juban NR, Zordilla Z. Optimizing PhilHealth's case-based payment scheme to achieve greater financial protection; 2016.

105. Cometto G, Buchan J, Dussault G. Developing the health workforce for universal health coverage. Bull World Health Organ. 2020;98(2):109.

106. Yip W, Fu H, Chen AT, Zhai T, Jian W, Xu R, et al. 10 years of health-care reform in China: progress and gaps in universal health coverage. Lancet. 2019;394(10204):1192-204.

107. Castro MC, Massuda A, Almeida G, Menezes-Filho NA, Andrade MV, de Souza Noronha KVM, et al. Brazil's unified health system: the first 30 years and prospects for the future. Lancet. 2019;394(10195):345-56.

108. Sarabi Asiabar A, Azami-Aghdash S, Rezapour A, Alaei Kalajahi R, Taghizadeh $\mathrm{S}$, Amuzadeh $\mathrm{S}$, et al. Economic consequences of outsourcing in public hospitals in Iran: a systematic review. J Health Admin. 2021;24(1):68-83.

109. Fantaye AW, Yaya S. Universal health coverage and facilitation of equitable access to Care in Africa. Front Public Health. 2019;7:102.

110. Giovanella L, Mendoza-Ruiz A, AdCA P, MCd R, Martins GB, Santos IS, et al. Universal health system and universal health coverage: assumptions and strategies. Ciencia Saude Coletiva. 2018;23:1763-76.

111. Khanghah HA, Janati A, Derakhshani N. A review of factors influencing health inequalities. Depiction Health. 2019;6(3):54-62.

112. Mathauer I, Torres LV, Kutzin J, Jakab M, Hanson K. Pooling financial resources for universal health coverage: options for reform. Bull World Health Organ. 2020;98(2):132.

113. Rodney AM, Hill PS. Achieving equity within universal health coverage: a narrative review of progress and resources for measuring success. Int J Equity Health. 2014;13(1):72.

114. Watkins DA, Qi J, Kawakatsu Y, Pickersgill SJ, Horton SE, Jamison DT. Resource requirements for essential universal health coverage: a modelling study based on findings from disease control priorities. Lancet Glob Health. 2020;8(6):e829-39.

115. Lozano R, Fullman N, Mumford JE, Knight M, Barthelemy CM, Abbafati C, et al. Measuring universal health coverage based on an index of effective coverage of health services in 204 countries and territories, 1990-2019: a systematic analysis for the global burden of disease study 2019. Lancet. 2020;396(10258):1250-84.

116. Koohpayehzadeh J, Azami-Aghdash S, Derakhshani N, Rezapour A, Kalajahi RA, Khasraghi JS, et al. Best practices in achieving universal health coverage: a scoping review; 2020

117. Organization WH. UHC law in practice: legal access rights to health care: country profiles: Germany, Japan, Kenya. Thailand: World Health Organization; 2019.

118. MAKOKHA TW. An examination of the legal, Policy and Institutional Framework for Universal Health Coverage in Kenya. University of Nairobi; 2019.

119. Abdullahi SA. Factors influencing the sustainability of universal health coverage in vulnerable livelihoods in Kenya: a case of Wajir County. University of Nairobi; 2018.

120. Vargas JR, Muiser J: Promoting universal financial protection: a policy analysis of universal health coverage in Costa Rica (1940-2000). Health Res Policy Syst 2013, 11(1):1-9.

121. Tangcharoensathien V, Pitayarangsarit S, Patcharanarumol W, Prakongsai P, Sumalee $H$, Tosanguan J, et al. Promoting universal financial protection: how the Thai universal coverage scheme was designed to ensure equity. Health Res Policy Syst. 2013;11(1):1-9.

122. Agyepong IA, Adjei S. Public social policy development and implementation: a case study of the Ghana National Health Insurance scheme. Health Policy Plan. 2008:23(2):150-60

123. Onoka CA, Onwujekwe OE, Uzochukwu BS, Ezumah NN: Promoting universal financial protection: constraints and enabling factors in scaling-up coverage with social health insurance in Nigeria. Health Res Policy Syst 2013, 11(1):1-10

124. Elhadi YAM, Adebisi YA, Abel UV, Daniel EM, Zaghloul A, III DEL-P: National health systems strengthening as the primary strategy to achieve Universal Health Coverage in African countries.

125. Reich MR, Harris J, Ikegami N, Maeda A, Cashin C, Araujo EC, et al. Moving towards universal health coverage: lessons from 11 country studies. Lancet. 2016;387(10020):811-6.

126. Milton B, Attree P, French B, Povall S, Whitehead M, Popay J. The impact of community engagement on health and social outcomes: a systematic review. Commun Dev J. 2012:47(3):316-34.
127. Walker C, Peterson CL. Universal health coverage and primary health care: Their place in people's health. J Eval Clin Pract. 2020.

128. Jahangiri R, Derakhshani N, Raeissi P, Alipour S, Ghasemyani S. Evaluation of the status of organizational culture among hospital staff in Iran: a systematic review and meta-analysis. Hosp Top. 2020:1-12.

129. Haldane V, Chuah FLH, Srivastava A, Singh SR, Koh GCH, Seng CK, et al. Community participation in health services development, implementation, and evaluation: a systematic review of empowerment, health, community, and process outcomes. PLoS One. 2019;14(5):e0216112.

130. Ranabhat CL, Kim C-B, Singh A, Acharya D, Pathak K, Sharma B, et al. Challenges and opportunities towards the road of universal health coverage (UHC) in Nepal: a systematic review. Arch Public Health. 2019;77(1):5.

131. Meng Q, Xu L. Monitoring and evaluating progress towards universal health coverage in China. PLoS Med. 2014;11(9):e1001694.

132. Alebachew A, Hatt L, Kukla M. Monitoring and evaluating progress towards universal health coverage in Ethiopia. PLoS Med. 2014;11(9):e1001696.

\section{Publisher's Note}

Springer Nature remains neutral with regard to jurisdictional claims in published maps and institutional affiliations.

\section{Ready to submit your research? Choose BMC and benefit from:}

- fast, convenient online submission

- thorough peer review by experienced researchers in your field

- rapid publication on acceptance

- support for research data, including large and complex data types

- gold Open Access which fosters wider collaboration and increased citations

- maximum visibility for your research: over $100 \mathrm{M}$ website views per year

At BMC, research is always in progress.

Learn more biomedcentral.com/submissions 